Middle East Journal of Science(MEJS)

journal homepage: http://mejs.ineseg.org/

\title{
EFFECT OF FLOW AND SEDIMENT CONCENTRATION ON SOME WATER QUALITY PARAMETERS IN MURAT RIVER
}

\section{Yasin Demir ${ }^{1}$ Azize Doğan Demir*2,}

${ }^{1}$ Bingöl Üniversitesi Ziraat Fakültesi Toprak Bilimi ve Bitki Besleme Bölümü, 12100, Bingöl, Türkiye



*ademir@bingol.edu.tr

The purpose of this study is to determine the effect of current-sediment quantity on some water quality parameters and to evaluate some characteristics waters of the Murat river. In the research, were used data of Palu and Akkonak observation stations on Murat river. According to the results of the study, it was determined that the values of water quality parameters decreased with increasing flow rate and sediment concentration in both stations. However, in order to make it clear that the relation between concentration-water quality parameters is meaningless, the result that the measurements in the stream must be made instantaneously and continuously has been put forward.

Key words: Murat river, flow, sediment, water quality 


\title{
MURAT NEHRINDE DEBI VE SEDIMENT KONSANTRASYONUNUN BAZI SU KALITE PARAMETRELERI ÜZERINE ETKISI
}

\begin{abstract}
Bu çalışmanın amacı Murat nehri sularının bazı özelliklerini değerlendirmek ve akım-sediment miktarının bazı su kalite parametreleri üzerine olan etkisini belirlemektir. Araştırma da Murat nehri üzerinde bulunan Palu ve Akkonak gözlem istasyonu verileri kullanılmıştır. Araştırma sonuçlarına göre her iki istasyonda akım miktarının ve sediment konsantrasyonun artmastyla su kalite parametrelerinin değerlerinin azaldiğ tespit edilmiştir. Ancak konsantrasyon-su kalite parametreleri arasındaki ilişkinin anlamsız olduğu, bunu net olarak ortaya koymak için ise de akarsudaki ölçümlerin anlık ve sürekli olarak yapılması gerektiği sonucu ortaya konmuştur.
\end{abstract}

Anahtar Kelimeler: Murat nehri, akım, sediment, su kalitesi

\section{Giriş}

Kullanılabilir su kaynaklarının kalitesi endüstriyel, tarımsal faaliyetler ile çevre ve canlıların bu kaynaklar üzerindeki etkisine bağlıdır. Su kirliliği bu faaliyetler sonucunda bazı kimyasal maddelerin veya çözünmesi güç katı maddelerin suya karışması sonucu meydana gelmektedir. Akarsulara değişik kaynaklardan materyal ulaşır ve suya ulaşan bu materyaller, başta su kalitesi olmak üzere birçok bileşene olumsuz etki yapmaktadır[1,2].

Sedimentasyon oluşumu genellikle yeryüzündeki kirletici materyallerin suya taşınmasıyla meydana gelmektedir[3,4]. Dolayısıyla sedimentin sularda meydana getireceği değişiklikler çevresel faktörlerin bir göstergesi olarak kabul edilmektedir[5,6]. Bununla birlikte havzalardan taşınan sedimentin özellikleri su kalitesinde bir indikatör olarak yaygın olarak kullanılmaktadır [7,8]. Suya karışan materyallerin su kalitesinde bırakacağı etkileri belirlemede su kalitesinin fiziksel ve kimyasal açıdan değerlendirilmesi suyun o anki durumu hakkında bilgi vermesi açısından oldukça önem taşımaktadır $[9,10]$.

Akarsular beslendikleri havzaların karakteristiklerinin yansıtırlar. Havzanın iklim ve toprak özellikleri suların fiziksel ve kimyasal özellikleri üzerine etkilidir. Bu çalışmada Furat nehrinin önemli bir kolu olan Murat nehri'ne ait su örneklerinin bazı parametreleri incelenmiştir. Bu bağlamda Murat nehri üzerinde Palu ve Akkonak sediment-su kalitesi gözlem istasyonlarında ölçülen akım ve sediment konsantrasyonu değerlerinin bazı su kalite parametreleri üzerindeki etkisi araştırılmıştır. 


\section{Yöntem}

Araştırma Murat nehri üzerinde 2102-Palu ve 2174-Akkonak sediment-su gözlem istasyonlarında, 1990-2010 yılları arasında Elektrik İşleri Etüt İdaresi (EİE) tarafından ölçülen su numunelerinin değerlendirilmesiyle yapılmıştır(Şekil 1). Araştırma kapsamındaki Akkonak gözlem istasyonunun yağış alanı $17435.1 \mathrm{~km} 2$, Palu gözlem istasyonunun yağış alanı $25515.6 \mathrm{~km} 2$ ve iki istasyon arasındaki uzaklık arasındaki uzaklık 230 km'dir. Çalışmada Palu gözlem istasyonundan 233 adet ve Akkonak gözlem istasyonunda 202 adet su numunesinin akım (m3/sn), sediment konsantrasyonu (ppm), EC $(\mu \mathrm{S} / \mathrm{cm}), \mathrm{pH}$, potasyum $(\mathrm{mg} / \mathrm{L})$, sodyum $(\mathrm{mg} / \mathrm{L})$, kalsiyum+magnezyum $(\mathrm{mg} / \mathrm{L})$, karbonat $(\mathrm{mg} / \mathrm{L})$, bikarbonat $(\mathrm{mg} / \mathrm{L})$, sülfat $(\mathrm{mg} / \mathrm{L})$ ve bor $(\mathrm{mg} / \mathrm{L})$ analiz değerleri incelenmiştir. Su örneklerine ait analiz sonuçları SPSS 18 paket programı kullanılarak tanımlayıcı istatistik değerleri ve akım-konsantrasyon bağımsız değişkenlerinin diğer bağımlı değişkenler üzerine olan etkisi analiz edilmiştir.

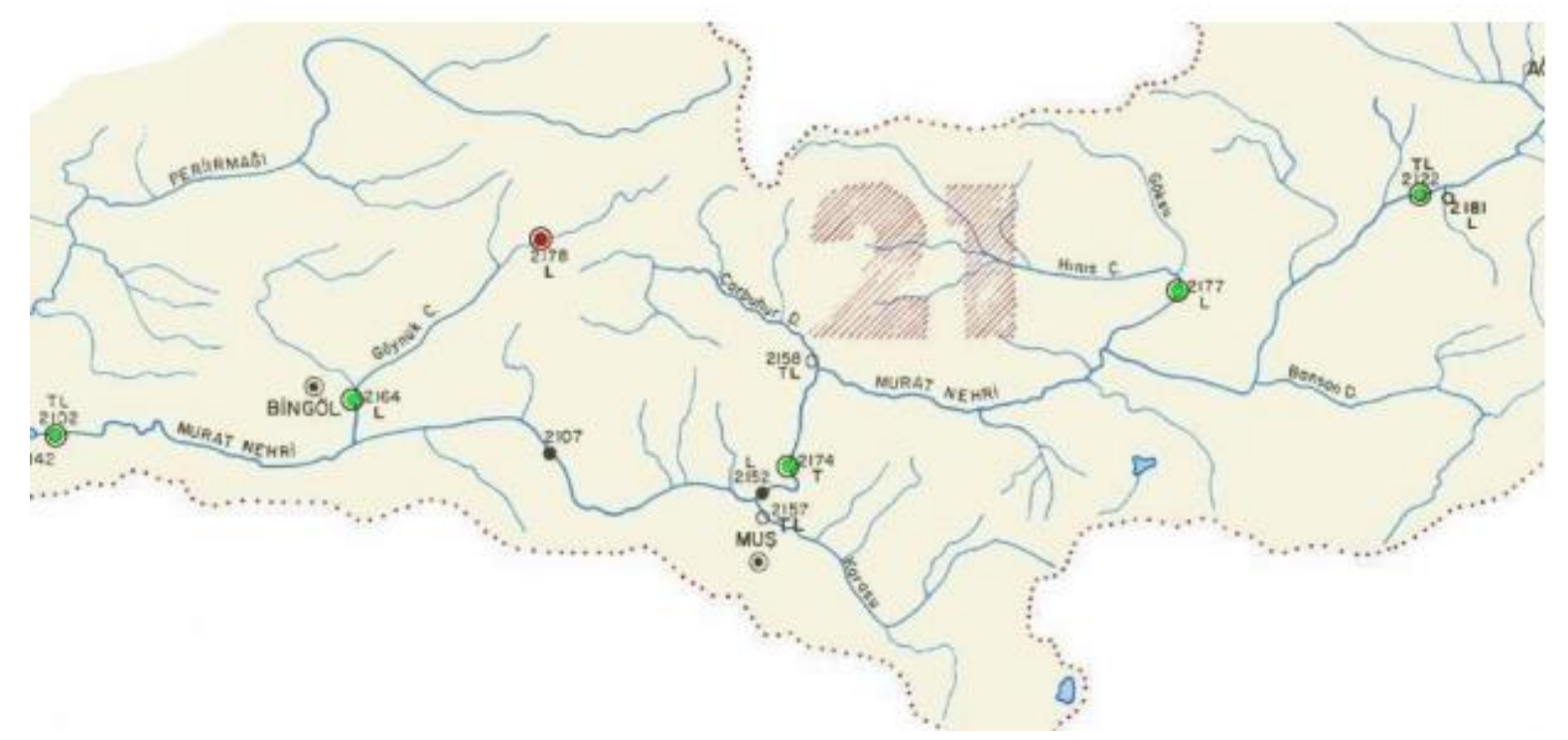

Şekil 1. Murat Nehri 2102 Palu ve 2174 Akkonak Gözlem İstasyonları (EİE, 2008)

\section{Bulgular}

Araştırma kapsamında incelenen gözlem istasyonlarından alınan su örneklerinin analiz sonuçlarına ait tanımlayıcı istatistik değerleri Tablo 1 ve Tablo 2'de verilmiştir. 
Tablo 1. Palu (2102) sediment-su kalitesi gözlem istasyonu su analizleri tanımlayıcı istatistikleri

\begin{tabular}{llllllll}
\hline & $\mathbf{N}$ & Minimum & Maximum & Ortalama & St.Hata & St.Sapma & Varyans \\
\hline Akım (m³/sn) & 233 & 14.33 & 2289.28 & 260.46 & 24.40 & 372.55 & 138798.7 \\
Konsantrasyon (ppm) & 233 & 20.92 & 12201.88 & 883.20 & 98.07 & 1497.09 & 2241279.13 \\
pH & 233 & 7.60 & 9.59 & 8.25 & 0.01 & 0.25 & 0.06 \\
EC ( $\mathbf{m}$ //cm) & 233 & 140.00 & 678.00 & 456.03 & 8.51 & 129.97 & 16893.54 \\
Sodyum (mg/L) & 233 & 0.23 & 3.91 & 1.70 & 0.04 & 0.74 & 0.55 \\
Potasyum (mg/L) & 233 & 0 & 0.30 & 0.08 & 0.002 & 0.05 & 0.002 \\
Kal-Mag (mg/L) & 233 & 0.70 & 4.49 & 2.97 & 0.04 & 0.68 & 0.46 \\
Karbonat (mg/L) & 233 & 0 & 1.16 & 0.30 & 0.014 & 0.22 & 0.04 \\
Bikarbonat (mg/L) & 233 & 0.12 & 3.92 & 2.68 & 0.04 & 0.66 & 0.44 \\
Klor (mg/L) & 233 & 0.12 & 2.63 & 1.31 & 0.04 & 0.63 & 0.39 \\
Sülfat (mg/L) & 233 & 0 & 1.62 & 0.46 & 0.02 & 0.33 & 0.11 \\
Bor $(\mathbf{m g} / \mathbf{L})$ & 233 & 0 & 0.85 & 0.23 & 0.01 & 0.16 & 0.03
\end{tabular}

Tablo 2. Akkonak (2174) sediment-su kalitesi gözlem istasyonu su analizleri tanımlayıcı istatistikleri

\begin{tabular}{|c|c|c|c|c|c|c|c|}
\hline & $\mathbf{N}$ & Minimum & Maximum & Ortalama & St.Hata & St.Sapma & Varyans \\
\hline Akım (m³/sn) & 202 & 9.56 & 1302.27 & 174.89 & 17.89 & 254.26 & 64651.59 \\
\hline Konsantrasyon (ppm) & 202 & 14.91 & 6786.83 & 506.43 & 61.96 & 880.67 & 775587.35 \\
\hline pH & 202 & 4.32 & 9.00 & 8.21 & 0.02 & 0.39 & 0.160 \\
\hline $\mathrm{EC}(\boldsymbol{\mu S} / \mathbf{c m})$ & 202 & 166.00 & 1172.00 & 550.23 & 14.28 & 203.00 & 41211.79 \\
\hline Sodyum (mg/L) & 202 & 0.33 & 6.95 & 2.34 & 0.09 & 1.34 & 1.81 \\
\hline Potasyum (mg/L) & 202 & 0 & 0.29 & 0.10 & 0.003 & 0.04 & 0.002 \\
\hline Kal-Mag (mg/L) & 202 & 0.84 & 5.19 & 3.23 & 0.06 & 0.91 & 0.83 \\
\hline Karbonat (mg/L) & 202 & 0 & 1.40 & 0.33 & 0.01 & 0.25 & 0.06 \\
\hline Bikarbonat (mg/L) & 202 & 0.54 & 4.57 & 2.90 & 0.05 & 0.84 & 0.71 \\
\hline Klor (mg/L) & 202 & 0.08 & 6.17 & 1.86 & 0.07 & 1.09 & 1.20 \\
\hline Sülfat (mg/L) & 202 & 0 & 6.29 & 0.59 & 0.05 & 0.73 & 0.53 \\
\hline Bor $(\mathrm{mg} / \mathrm{L})$ & 202 & 0 & 1.04 & 0.33 & 0.01 & 0.21 & 0.04 \\
\hline
\end{tabular}

Su örneklerinin tanımlayıcı istatistik sonuçlarına bakıldığında Palu gözlem istasyonunda ortalama debi $260.46 \mathrm{~m} 3 / \mathrm{sn}$ iken bu değer Akkonak istasyonunda $174.89 \mathrm{~m} 3 / \mathrm{sn}$ olarak ölçülmüştür. İki istasyona ait 20 yıllık ortalama debi değerleri farkı 85.57 m3/sn olarak hesaplanmıştır. Su örneklerindeki sediment konsantrasyon değerlerine bakıldığında Palu istasyonunda ortalama $883.20 \mathrm{ppm}$, Akkonak istasyonunda 506.43 ppm olarak ölçülmüştür. Yine analiz sonuçlarına göre Palu istasyonundaki su konsantrasyonu Akkonak istasyonundan 376.23 ppm daha yoğundur. Bu durum Palu istasyonu yağış havzasından murat nehrine taşınan sediment miktarı boyutunun bir göstergesidir.

Akarsu debisinin ve su sdiment konsantrasyonunun kalite parametrelerine olan etkisini değerlendirmek amacıyla yapılan korelasyon analizi Tablo 3'te gösterilmiştir. Tabloya göre bağımsız değişkenler (konsantrasyon, debi) ile bağımlı değişkenler (EC, pH, potasyum, sodyum, kalsiyum+magnezyum, karbonat, bikarbonat, klor, sülfat, ve bor), arasında önemli ilişkiler saptanmıştır. Palu istasyonunda ölçülen debi ile suların $\mathrm{EC}, \mathrm{Na}, \mathrm{Ca}+\mathrm{Mg}$, ve $\mathrm{Cl}$ içerikleri arasında önemli $(\mathrm{p}<0,01)$ negatif ilişkiler belirlenmiştir. Aynı şekilde Akkonak istasyonunda debi ile su örneklerinin $\mathrm{EC}, \mathrm{K}, \mathrm{Ca}+\mathrm{Mg}, \mathrm{CO} 3, \mathrm{HCO} 3$, $\mathrm{Cl}$, SO4 ve B içerikleri arasında önemli $(\mathrm{p}<0,01)$ negatif ilişkiler saptanmıştır. Palu istasyonunda debi $\mathrm{pH}$, debi - K, debi - CO3, debi- SO4 ve debi - B ikilileri arasında herhangi bir ilişki belirlenmemiştir. Bunun yanında Akkonak istasyonunda sadece debi-pH arasında bir ilişki saptanmamıştır. 
Tablo 3. 2102 Palu ve 2174 Akkonak gözlem istasyonları su örneklerine ait bazı özelliklerin korelasyon analizi

\begin{tabular}{lllll}
\hline & Palu & & Akkonak & \\
\hline & $\begin{array}{l}\text { Konsantrasyon } \\
(\mathbf{p p m})\end{array}$ & $\begin{array}{l}\text { Akım } \\
\left(\mathbf{m}^{3} / \mathbf{s n}\right)\end{array}$ & $\begin{array}{l}\text { Konsantrasyon } \\
(\mathbf{p p m})\end{array}$ & $\begin{array}{l}\text { Akım } \\
\left(\mathbf{m}^{3} / \mathbf{s n}\right)\end{array}$ \\
\hline $\mathbf{p H}$ & $-.350^{* *}$ & .008 & -.077 & -.138 \\
$\mathbf{E C}(\boldsymbol{\mu} \mathbf{S} / \mathbf{c m})$ & $-.436^{* *}$ & $-.213^{* *}$ & $-.389^{* *}$ & $-.651^{* *}$ \\
Sodyum $(\mathbf{m g} / \mathbf{L})$ & $-.453^{* *}$ & $-.217^{* *}$ & $-.307^{* *}$ & $-.612^{* *}$ \\
Potasyum $(\mathbf{m g} / \mathbf{L})$ & $-.302^{* *}$ & -.080 & $-.311^{* *}$ & $-.516^{* *}$ \\
Kal-Mg $(\mathbf{m g} / \mathbf{L})$ & $-.311^{* *}$ & $-.181^{* *}$ & $-.317^{* *}$ & $-.541^{* *}$ \\
Karbonat $(\mathbf{m g} / \mathbf{L})$ & $-.341^{* *}$ & -.087 & -.105 & $-.238^{* *}$ \\
Bikarbonat $(\mathbf{m g} / \mathbf{L})$ & $-.242^{* *}$ & $-.167^{*}$ & $-.350^{* *}$ & $-.564^{* *}$ \\
Klor $(\mathbf{m g} / \mathbf{L})$ & $-.497^{* *}$ & $-.204^{* *}$ & $-.388^{* *}$ & $-.594^{* *}$ \\
Sülfat $(\mathbf{m g} / \mathbf{L})$ & -.037 & -.087 & .022 & $-.232^{* *}$ \\
Bor $(\mathbf{m g} / \mathbf{L})$ & $-.366^{* *}$ & -.076 & $-.185^{* *}$ & $-.203^{* *}$ \\
\hline
\end{tabular}

$* * \mathrm{p}<0.01, * \mathrm{p}<0.05$

Suların sediment konsantrasyon değerleri ile su kalite parametreleri arasında önemli ilişkiler saptanmıştır. Her iki istasyonda da sediment konsantrasyonu ile su örneklerinin $\mathrm{EC}, \mathrm{Na}, \mathrm{K}, \mathrm{Ca}+\mathrm{Mg}$, $\mathrm{HCO} 3, \mathrm{Cl}$ ve $\mathrm{B}$ içerikleri arasında önemli $(\mathrm{p}<0,01)$ negatif ilişkiler saptanmıştır. Aynı şekilde her iki istasyonda da konsantrasyon ile SO4 arasında herhangi bir ilişki tespit edilmemiştir. Ancak Palu istasyonundan alınan su örneklerinde Akkonak istasyonundan farklı olarak konsantrasyon-pH ve konsantrasyon-CO3 ikilileri arasında önemli $(\mathrm{p}<0.01)$ negatif ilişkinin olduğu tespit edilmiştir. $\mathrm{Bu}$ sonuçlara göre sulardaki sediment yoğunluğunun artmasıyla ters orantılı olarak bazı su kalite parametrelerinin azaldığı sonucu çıkmaktadır. Ancak bu parametrelerin azalması konsantrasyondan daha çok suyun debisinin artmasının daha etkili olduğu görüşü ile açıklanabilir. Diğer bir ifade ile akım miktarının artmasıyla sudaki erimiş madde konsantrasyonun azalması su kalite parametre değerlerini azalmasına neden olmuştur. Çelebi ve ark (1997) tarafından Murat nehri üzerinde yapılan bir çalışmada benzer bir sonuç bulunmuştur. Çalışmada askıda katı madde miktarının akıma bağlı olduğu ve çözünmüş haldeki element derişimleri (Ca- K, Zn, Fe) ile askıdaki katı maddenin element derişimleri arasında belirgin ilişkinin olmadığını bildirmiştir. Bu durumda askıdaki katı maddenin çözünmediği zaman suyun element derişimine etkisinin olmadığı söylenebilir. Dolayısıyla akımın artmasıyla sediment konsantrasyonun arttığı ve bazı su kalite parametre değerlerinin azaldığı sonucu çıkarılabilir.

Araştırmaya konu olan Murat nehri üzerindeki iki gözlem istasyonunun akım sediment değerleri arasındaki ilişki Şekil 2'de verilmiştir. 

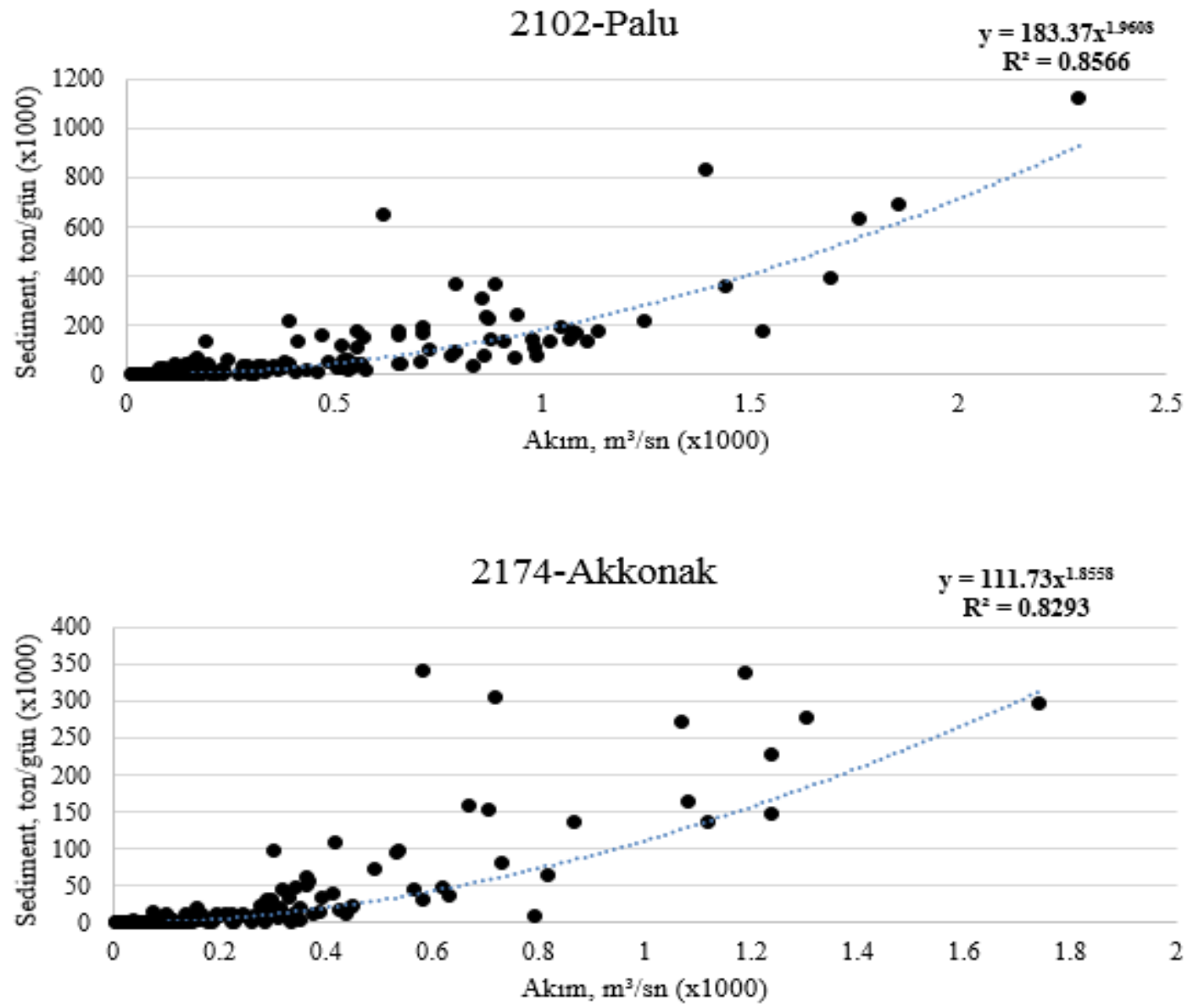

Şekil 2. Palu ve Akkonak sediment gözlem istasyonlarına ait akım ve sediment yükü ilişkisi (19902011)

Şekilden de anlaşılacağı gibi her iki istasyonda da akım ve sediment verimi arasında önemli bir ilişki bulunmuştur. Küresel ısınmanın etkisiyle birçok araştırmacı havzalardan akarsulara taşınan sediment miktarını ve buna bağlı olarak sularda meydana gelebilecek değişiklikleri incelemek amacıyla çalışmalara yapmışlardır. Yapılan çalışmalarda akarsularda debi miktarının artmasıyla sediment konsantrasyonunda arttı̆ğ tespit edilmiştir[11].

\section{Sonuçlar}

Murat nehri üzerinde Palu ve Akkonak su gözlem istasyonlarında 1990-2010 yılları arasında ölçülen su özellikleri bu çalışmada incelenmiş, akım ve konsantrasyon miktarının artmasıyla bazı su kalite parametrelerinin azaldığı belirlenmiştir. Konsantrasyon- su parametreleri arasındaki bağıntının ancak sediment element içeriğinin analiz edilmesiyle belirleneceği sonucu elde edilmiştir. Yine aynı istasyonlarda akım miktarının artmasıyla sediment miktarının arttığı ortaya çıkmıştır. Bu durum bölgedeki erozyonun ciddi bir sorun olduğunu göstermektedir. 
Akkonak istasyonundan bir sonraki gözlem istasyonu Palu gözlem istasyonunda ölçülen sediment konsantrasyonu Akkonak istasyonuna göre 376,23 ppm daha daha fazla çıkmıştır. Buda Palu yağış havzasından yaklaşık 5106,2 ton/gün kadar bir sediment taşınımının alandan taşındığını göstermektedir. Günümüzde akarsularda gözlem istasyonlarında yapılan ölçümlerin geleneksel metot yerine sürekli ve anlık ölçümler yapan akustik ve lazer ölçüm metotlarının kullanılması gerekmektedir. Zira belirli aralıklarla yapılan ölçümlerde elde edilen sonuçlar, düzensiz yağış rejiminden dolayı gerçeği tam olarak yansıtmayabilir. Bu durumda sorunların çözülmesi için yapılan çalışmalar etkisiz olabilmektedir.

Akarsularda gözlem ağının genişletilmesi ve yeni metotlarla ölçümlerin anlık yapılması, su kalitesi üzerine etkili yağış, sediment yoğunluğu, taşınan materyalin özelliklerini ve etki derecesini daha da belirgin kılacaktır. Her iki istasyonda ortalama EC değerinin $250 \mu \mathrm{S} / \mathrm{cm}$ 'den fazla olması Sulama suyu kalitesi bakımından bu suların ikinci sınıf sulama suyu olduğunu göstermektedir. Bu durumda havzalarda akarsulara taşınan suların daha da temiz olması için erozyon bölgeleri belirlenmelidir. Belirlenen riskli alanlarda rehabilitasyon ve toprak koruma çalışmaları biran önce yapılmalıdır. 


\section{Kaynakça}

[1] Aküzüm, T. ve F. Öztürk, 1996. Topraksu Yap 1 lar 1 . Ankara Üniv. Ziraat Fak. Yay 1 n No:1448, 521 s., Ankara.

[2] Apaydin, H., Karaş, E. (2003). Kurukavak deresi havzasında yüzey akış ve sediment miktarının AGNPS modeli ile tahmini. Tarim Bilimleri Dergisi, 9(3), 344-351.

[3] Ansari, A.A., Singh, I.B., Tobschall, H.J., 2000. Importance of geomorphology and sedimentation processes for metal dispersion in sediments and soils of the Ganga Plain: identification of geochemical domains. Chem. Geol. 162 (3-4), 245-266

[4] Chatterjee, M., Silva Filho, E.V., Sarkar, S.K., Sella, S.M., Bhattacharya, A., Satpathy, K. K., Prasad, M.V.R., Chakraborty, S., Bhattacharya, B.D., 2007. Distribution and possible source of trace elements in the sediment cores of a tropical macrotidal estuary and their ecotoxicological significance. Environ. Int. 33, 346-356

[5] Çelebi, H., Utlu, A. G. F., Peker, İ. (1997). Murat Nehrinin Hidrojeokimyasal Özellikleri. Çevre Dergisi, 22, 14-20.

[6] Demir, A. D., Demir, Y. (2016). Murat nehri Palu yağış havzasından taşınan süspanse sediment miktarının zamansal değişiminin değerlendirilmesi. Iğdır Üniversitesi Fen Bilimleri Enstitüsü Dergisi, 6(2), 61-68.

[7] EİE (2008). Türkiye Akarsularında Su Kalitesi Gözlemleri. Ankara

[8] Nath, B.N., Kuzendory, H., Pluger, W.L., 2000. Influence of provenance weathering and sedimentary process on the elemental ratios of the fine-grained fractions of the bed load sediments from Vembanad Lake and the adjoining continental shelf, south west coast of India. J. Sediment. Petrol. 70, 1081-1094.

[9] Jueyi, S. U. I., Yun, H. E., Cheng, L. I. U. (2009). Changes in sediment transport in the Kuye River in the Loess Plateau in China. International Journal of Sediment Research, 24(2), 201-213.

[10] Somura, H., Takeda, I., Arnold, J.G., Mori, Y., Jeong, J., Kannan, N., Hoffman, D., 2012. Impact of suspended sediment and nutrient loading from land uses against water quality in the Hii River basin, Japan. J. Hydrol. 450-451 (11), 25-35.

[11] Walling D E and Fang D. 2003, Recent trends in the suspended sediment transport modulus of the world rivers. Global and Planetary Change, Vol. 39, pp. 111-126. 